\title{
Trench-parallel flow and seismic anisotropy in the Mariana and Andean subduction systems
}

\author{
Erik A. Kneller ${ }^{1} \&$ Peter E. van Keken ${ }^{1}$
}

Shear-wave splitting measurements above the mantle wedge of the Mariana $^{1}$ and southern Andean ${ }^{2,3}$ subduction zones show trenchparallel seismically fast directions close to the trench and abrupt rotations to trench-perpendicular anisotropy in the back arc. These patterns of seismic anisotropy may be caused by threedimensional flow associated with along-strike variations in slab geometry $^{1-5}$. The Mariana and Andean subduction systems are associated with the largest along-strike variations of slab geometry observed on Earth $^{6,7}$ and are ideal for testing the link between slab geometry and solid-state creep processes in the mantle. Here we show, with fully three-dimensional non-newtonian subduction zone models, that the strong curvature of the Mariana slab and the transition to shallow slab dip in the Southern Andes give rise to strong trench-parallel stretching in the warm-arc and warm-backarc mantle and to abrupt rotations in stretching directions that are accompanied by strong trench-parallel stretching. These models show that the patterns of shear-wave splitting observed in the Mariana and southern Andean systems may be caused by significant three-dimensional flow induced by along-strike variations in slab geometry.

Shear-wave splitting occurs when shear waves propagate through anisotropic material and split into two orthogonally polarized waves that travel at different velocities ${ }^{5}$. This type of seismic anisotropy is a straightforward indicator of elastic structure and provides information about lattice preferred orientation and flow geometry within the mantle ${ }^{5}$. The most commonly observed fabric in dry peridotite is A-type, which causes alignment of the seismically fast splitting axis with the maximum stretch direction or flow direction for simple shear. Shear-wave splitting observations from most subduction zones show complex patterns of seismic anisotropy that usually have trench-parallel fast directions ${ }^{8}$. These observations are unexpected, because models of two-dimensional wedge flow predict fast seismic anisotropy parallel to plate motion (trench perpendicular) ${ }^{9}$. Possible causes for trench-parallel anisotropy and abrupt rotations in fast directions in the mantle wedge of subduction zones include olivine fabric transitions $^{10-12}$, melt-related anisotropy ${ }^{13,14}$ and three-dimensional flow with stretching-parallel olivine fabrics ${ }^{4}$. Three-dimensional flow may be caused by small-scale convection ${ }^{15}$, oblique subduction ${ }^{16}$, differential slab rollback ${ }^{17}$, trench-parallel motion of the overriding plate ${ }^{4}$, and variations in slab geometry ${ }^{4,16}$. Testing the applicability of these models to specific subduction systems will improve our ability to infer flow geometry from seismic observations and provide better constraints on thermal structure and geochemical transport processes.

Whereas melt-related processes and olivine fabric transitions are applicable to local regions of the mantle wedge $e^{8,12}$, three-dimensional flow has the potential to explain the trench-parallel shear-wave splitting that is widespread in some subduction zones. Here we explore the effects of slab geometry on deformation in the mantle wedge of segments of the Mariana and Andean subduction systems. The modelled segments show strong along-strike variation in slab curvature (Mariana) and dip (Andes). Both geometrical changes induce alongstrike pressure changes that lead to significant three-dimensional flow. Accurate modelling of the magnitude of the velocity and strain geometry in the mantle wedge requires fully three-dimensional highresolution calculations with realistic stress- and temperaturedependent rheology (see Methods Summary).
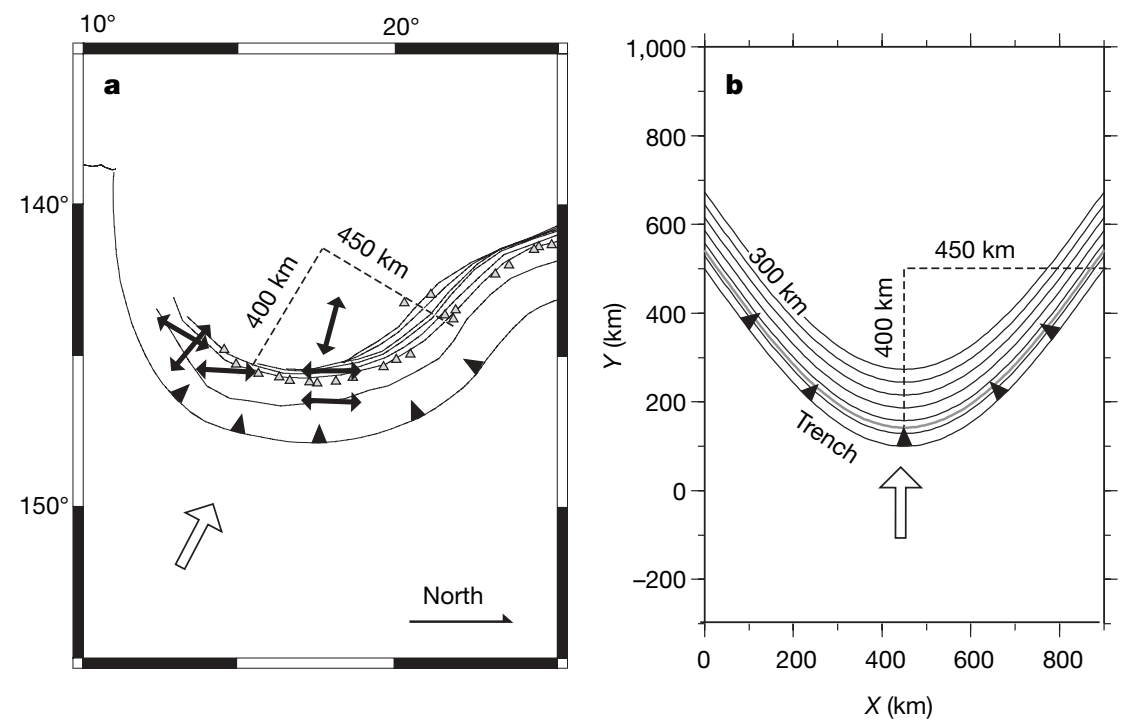

Figure 1 | Observations and approximate slab model of the Mariana subduction system. Contours show the depth to slab at $50 \mathrm{~km}$ intervals ${ }^{6}$. The hachured lines (solid black triangles) indicate the trench and dip direction. Dashed lines show the length scales of slab curvature. The open arrow denotes the relative convergence direction of the Pacific plate with respect to the Philippine plate. a, Geometry of the Mariana subduction system between $10^{\circ}-25^{\circ} \mathrm{N}$ (horizontal axis) and $135^{\circ}-155^{\circ} \mathrm{E}$ (vertical axis). Black double arrows show the pattern of seismically fast directions associated with localshear-wave phases ${ }^{1}$. The positions of the Holocene volcanoes (grey triangles) are from the Smithsonian Institution, Global Volcanism Program (http://www.volcano.si.edu). b, Simplified slab model. Black solid lines denote $50-\mathrm{km}$ slab contours, whereas the grey line denotes the depth at which full viscous coupling between the slab and mantle wedge starts. 

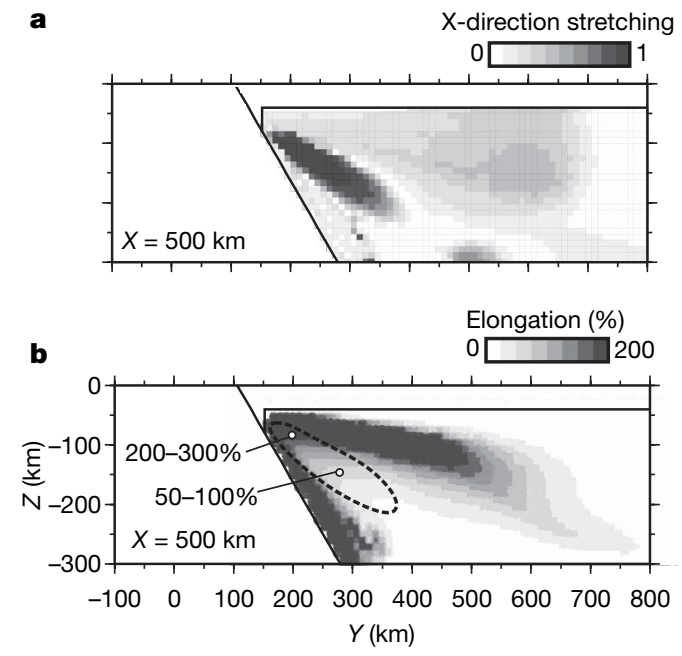

The characteristic amplitude and width of the curvature of the Mariana slab are approximately 400 and $900 \mathrm{~km}$, respectively ${ }^{6}$ (Fig. 1a). We construct a simplified model of the Mariana slab with a constant slab dip of $60^{\circ}$ in the convergence direction and describe slab curvature with a harmonic function (Fig. 1b; Supplementary Fig. 1b). The magnitude of the trench-parallel velocity in the mantle wedge increases towards the trench and reaches a maximum in the arc mantle (Supplementary Fig. 2a and b). This is caused by the strong curvature in the slab and gives rise to a radiating flow geometry. Strong focusing of the flow occurs where curvature is largest, owing to the local decrease in viscosity associated with the strainrate-dependent and temperature-dependent rheology.

Finite-strain calculations for the Mariana model show trenchparallel stretching in the arc mantle and an abrupt change to trench-perpendicular stretching in the back arc (Fig. 2). This region of strong trench-parallel stretching is associated with the strongest velocity gradients and is located between 80 and $150 \mathrm{~km}$ depth (Fig. 2a and $\mathrm{b}$ ). The maximum thickness is around $50 \mathrm{~km}$, which is consistent (assuming maximum fabric strength and a total intrinsic anisotropy of around 6-7\%; ref. 18) with a maximum delay time for split shear waves of approximately $0.5-1 \mathrm{~s}$. Recent local-shear-wave splitting measurements above the mantle wedge of the Mariana subduction zone show trench-parallel fast directions in the arc mantle, a rotation to trench perpendicular in the back arc, and delay times of around $1 \mathrm{~s}$ (ref. 1). The similarities between shear-wave splitting observations (Fig. 1a) and calculated stretching patterns (Fig. 2c) suggest that anisotropy in the Mariana wedge is controlled by three-dimensional stretching induced by slab curvature.

In the Andean subduction system large variations in slab dip occur near flat slab subduction ${ }^{6,7}$. For example, a transition from average slab dip equal to $30^{\circ}$ to less than $5^{\circ}$ over $400 \mathrm{~km}$ is observed adjacent to the flat slab in the Chile-Argentina region ${ }^{2,3,7}$ (Fig. 3a). We construct an approximate model of the Chile-Argentina slab, using a linear trench and a harmonic function that describe slab dip variations along strike (Fig. 3b; Supplementary Fig. 1c). For the Andean model, average slab dip varies from $30^{\circ}$ at $X=400 \mathrm{~km}$ to $10^{\circ}$ at $X=0 \mathrm{~km}$, which is similar to the geometry of the Chile-Argentina slab (Supplementary Fig. 3).

Our fluid dynamic model shows relatively low dynamic pressure near the shallow dipping slab, which drives strong trench-parallel flow (Supplementary Fig. 4). The calculated flow geometry consists of flow lines that are parallel to the trench near the shallow dipping slab and trench-perpendicular directly above the shallow dipping slab. The magnitude of trench-parallel flow reaches a maximum close to the convergence velocity in the region where the slab is at 75$100 \mathrm{~km}$ depth (Supplementary Fig. 4c and d). Strong trench-parallel focusing of flow occurs in the corner of the mantle wedge next to the shallow dipping slab (Supplementary Fig. 4a). This flow geometry leads to a complicated pattern of deformation with strong trenchparallel stretching in the shallow mantle to the right (south) of the shallow dipping segment. The stretching abruptly becomes trenchperpendicular directly above the shallow dipping slab (Fig. 4a and b).
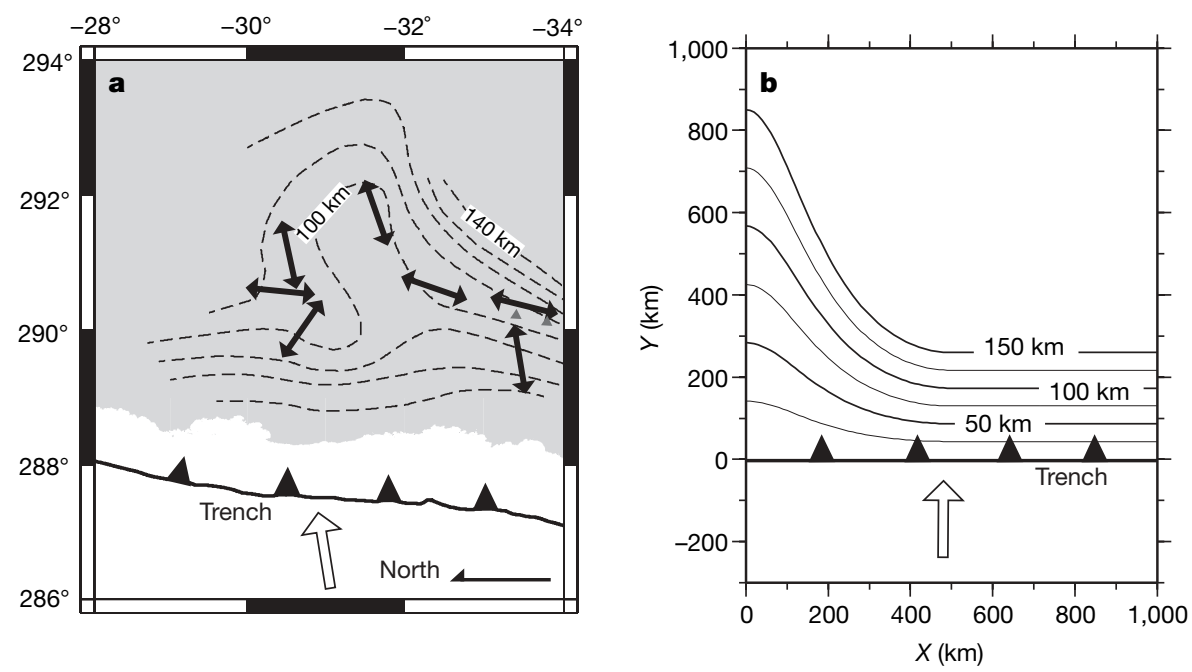

Figure 3 | Observations and approximate slab model of the Andean subduction system. a, Dashed lines show contours (10 km contour interval) of the subducting slab in the Northern Chile region of the Andean subduction system ${ }^{7}$. The grey shading in a indicates land. $\mathbf{b}$, Simplified slab geometry used in this study. The average slab dip in a varies from less than $5^{\circ}$ to $30^{\circ}$ over $400 \mathrm{~km}$. Bold arrows show the observed fast splitting directions ${ }^{2,3}$. The slab geometry used in the Andean model presented in this work (b) has a similar variation in average slab $\operatorname{dip}\left(10^{\circ}\right.$ to $\left.30^{\circ}\right)$ (Supplementary Fig. 1c). See Fig. 1 for further details. 

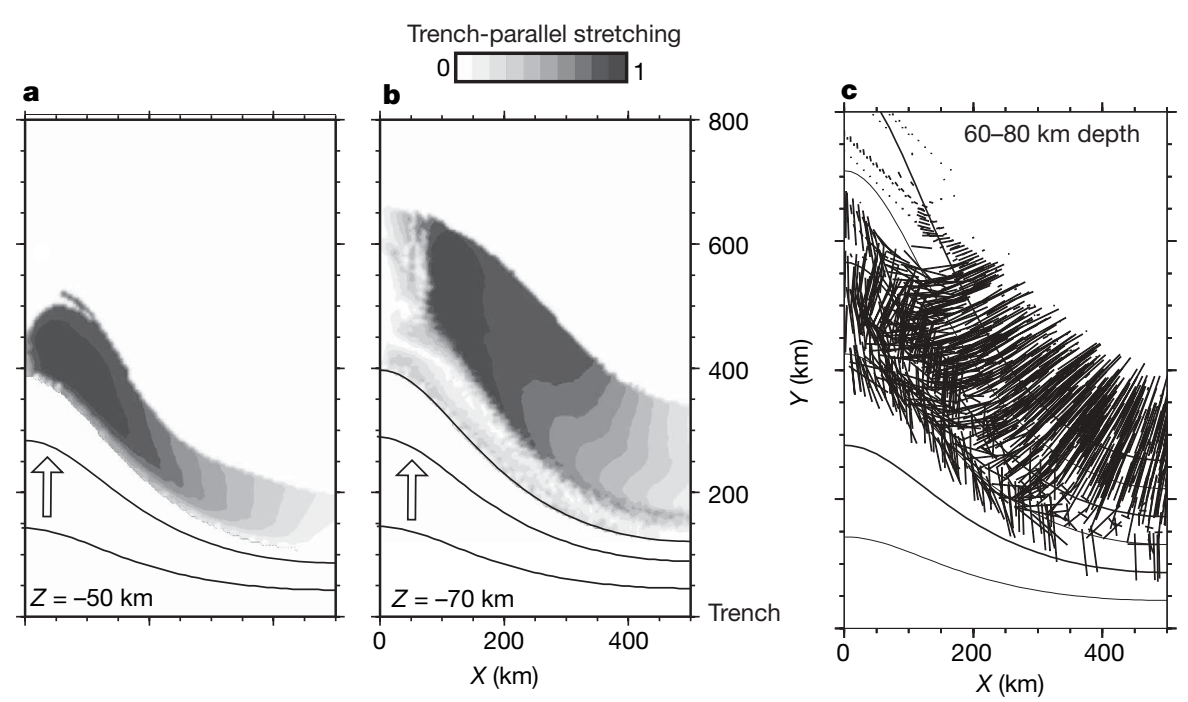

Figure 4 | Finite strain calculations from the Andean model. a, b, Maps showing the magnitude of trench-parallel stretching. c, Maximum stretch axes. d, Vertical crosssection of trench-parallel stretching at $X=200$ $\mathrm{km}$ for the Andean model. See Fig. 2 for details. The magnitude of trench-parallel stretching is shown only for particles that have undergone greater than $50 \%$ elongation. This slab geometry is associated with thick layers of material with convergence-normal stretching in the arc and back-arc mantle.

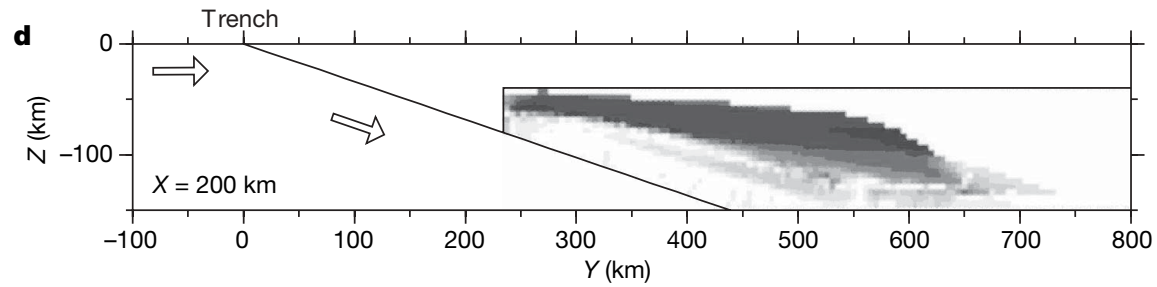

A relatively thick layer of material with trench-parallel stretching develops in the mantle wedge with strain magnitudes exceeding 300\% (Fig. 4c).

Trench-parallel shear-wave splitting and a rotation to trenchperpendicular splitting are observed with both teleseismic and local-shear-wave phases in the Chile-Argentina region of the Andean system $^{2,3}$ (Fig. 3a). These observations suggest the presence of strong trench-parallel stretching in the arc mantle, strong focusing and stretching in the corner of the mantle wedge adjacent to the flat slab, and a rapid rotation to trench-perpendicular stretching towards the flat slab segment. This inferred pattern of deformation (Fig. 3a) is strikingly similar to the pattern of stretching from the model presented here (Fig. $4 \mathrm{a}$ and b). This suggests that the strain field within this portion of the Andean wedge is controlled by three-dimensional variations in slab dip. Slab dip variations may also play an important role in controlling seismic anisotropy in the mantle wedge next to the flat slab of the Northern Andean Subduction system ${ }^{19}$, which is associated with a similar transition to shallow dip, but over a distance of 900-1,000 km.

Three-dimensional flow plays an important role in a variety of processes occurring in the subduction factory such as thermal structure, geochemical transport, and rock fabric development. The shearwave splitting observations and the calculations presented in this work demonstrate that models of slab metamorphism, arc magma production, and rock fabric development should consider threedimensional flow in systems with large variations in slab geometry. We conclude that strong three-dimensional flow exists in the Mariana and Andean subduction systems and that this flow significantly affects the formation of seismic anisotropy in the mantle wedge.

\section{METHODS SUMMARY}

Solid-state creep in the mantle wedge is driven by a kinematically prescribed slab with along-strike variations of slab dip and trench-curvature defined by simple function $\mathrm{s}^{20}$ (Supplementary Fig. 1). An experimentally based temperature- and stress-dependent rheology is implemented in the viscous wedge $e^{21,22}$. Temperature, velocity and dynamic pressure are obtained by numerically solving equations that govern heat transport and fluid flow with the finite element method. Large gradients in velocity and viscosity require the implementation of a high-resolution mesh with strong local refinement in the corner of the mantle wedge. Particle motion and finite strain are calculated using the steady-state velocity field. Integrated maximum stretch directions are used as proxy for olivine lattice preferred orientation and seismically fast directions in the warm-arc and warm-back-arc mantle. This proxy provides a reasonable approximation for olivine lattice-preferred-orientation development throughout most of the mantle wedge for the cases considered in this study because particles experience consistent velocity gradients as they travel through the mantle wedge $e^{23,24}$.

Full Methods and any associated references are available in the online version of the paper at www.nature.com/nature.

\section{Received 1 May; accepted 18 October 2007.}

1. Pozgay, S. H., Wiens, D. A., Conder, J. A., Shiobara, H. \& Sugioka, H. Complex mantle flow in the Mariana subduction system: evidence from shear wave splitting. Geophys. J. Int. 170, 371-386 (2007).

2. Anderson, M. L., Zandt, G., Triep, E., Fouch, M. \& Beck, S. Anisotropy and mantle flow in the Chile-Argentina subduction zone from shear wave splitting analysis. Geophys. Res. Lett. 31, doi:10.1029/2004GL020906 (2004).

3. Anderson, M., Zandt, G. \& Wagner, L. Along-strike mantle flow variations in a segment of the South American Subduction zone, Chile and Argentina. Earth Planet. Sci. Lett. (submitted).

4. Hall, C. E., Fischer, K. M., Parmentier, E. M. \& Blackman, D. K. The influence of plate motions on three-dimensional back arc mantle flow and shear wave splitting. J. Geophys. Res. 105, $28009-28033$ (2000).

5. Park, J. \& Levin, V. Seismic anisotropy: tracing plate dynamics in the mantle. Science 296, 485-489 (2002).

6. Syracuse, E. M. \& Abers, G. A. Global compilation of variations in slab depth beneath arc volcanoes and implications. Geochem. Geophys. Geosyst. 7, doi:10.1029/2005GC001045 (2006).

7. Anderson, M., Alvarado, P., Zandt, G. \& Beck, S. Geometry and brittle deformation of the subducting Nazca plate, central Chile and Argentina. Geophys. J. Int. 171, doi:10.1111/j.1365-246X.2007.03483.x (2007).

8. Wiens, D. A. \& Smith, G. P. in Inside The Subduction Factory (ed. Eiler, J.) 83-105 (Geophysical Monograph 138, American Geophysical Union, Washington DC (2003).

9. Fischer, K. M., Parmentier, E. M., Stine, A. R. \& Wolf, E. Modelling anisotropy and plate-driven flow in the Tonga subduction zone back arc. J. Geophys. Res. 105 181-191 (2000).

10. Kneller, E. A., van Keken, P. E., Karato, S. \& Park, J. B-type olivine fabric in the mantle wedge: Insights from high-resolution non-Newtonian subduction zone models. Earth Planet. Sci. Lett. 237, 781-797 (2005).

11. Katayama, I. \& Karato, S. Effect of temperature on the B- to C-type olivine fabric transition and implication for flow pattern in subduction zones. Phys. Earth Planet. Inter. 157, 33-45 (2006). 
12. Kneller, E. A., van Keken, P. E., Katayama, I. \& Karato, S. Stress, strain, and B-type olivine fabric in the fore-arc mantle: sensitivity tests using high-resolution steadystate subduction zone models. J. Geophys. Res. 112, B04406, doi:10.1029/ 2006JB004544 (2007).

13. Holtzman, B. K. et al. Melt segregation and strain partitioning: implications for seismic anisotropy and mantle flow. Science 301, 1227-1230 (2003).

14. Kendall, J., Stuart, G. W., Ebinger, C. J., Bastow, I. D. \& Keir, D. Magma-assisted rifting in Ethiopia. Nature 433, 146-148 (2005)

15. Honda, S. \& Saito, M. Small-scale convection under the back-arc occurring in the low viscosity wedge. Earth Planet. Sci. Lett. 216, 703-715 (2003).

16. Mehl, L., Hacker, B. R., Hirth, G. \& Kelemen, P. B. Arc-parallel flow within the mantle wedge. Evidence from the accreted Talkeetna arc, south central Alaska. J. Geophys. Res. 108, doi:10.1029/2002JB002233 (2003)

17. Russo, R. M. \& Silver, P. G. Trench-parallel flow beneath the Nazca plate from seismic anisotropy. Science 263, 1105-1111 (1994).

18. Ismail, B. W. \& Mainprice, D. An olivine fabric database: an overview of upper mantle fabrics and seismic anisotropy. Tectonophysics 196, 145-157 (1998)

19. Kaneshima, S. \& Silver, P. G. Anisotropic loci in the mantle beneath central Peru. Phys. Earth Planet. Inter. 88, 257-272 (1995).

20. Kneller, E. A. \& van Keken, P. E. The effect of three-dimensional slab geometry on deformation in the mantle wedge: implications for shear wave anisotropy. Geochem. Geophys. Geosyst. (in the press).
21. Karato, S. \& Jung, H. Effects of pressure on high-temperature dislocation creep in olivine. Phil. Mag. 83, 401-414 (2003).

22. Mei, S. \& Kohlstedt, D. L. Influence of water on plastic deformation of olivine aggregates. 1. Diffusion creep regime. J. Geophys. Res. 105, 21457-21469 (2000).

23. Kaminski, E. \& Ribe, N. M. Time scales for the evolution of seismic anisotropy in mantle flow. Geochem. Geophys. Geosyst. 158, 744-752 (2002).

24. Lassak, T. M., Fouch, M. J., Hall, C. E. \& Kaminski, E. Seismic characterization of mantle flow in subduction systems: can we resolve a hydrated mantle wedge? Earth Planet. Sci. Lett. 243, 632-649 (2006).

Supplementary Information is linked to the online version of the paper at www.nature.com/nature.

Acknowledgements We thank $M$. Anderson for providing slab contours of the southern Andean slab and insights on possible deformation processes in the Andean mantle wedge. We thank S. Pozgay and D. Wiens for discussions on the origin of trench-parallel anisotropy in the Mariana subduction system. We also thank G. Abers and E. Syracuse for discussions on three-dimensional slab geometry and kinematics. This research was supported by the National Science Foundation.

Author Information Reprints and permissions information is available at www.nature.com/reprints. Correspondence and requests for materials should be addressed to E.A.K. (ekneller@umich.edu). 


\section{METHODS}

Model set-up. Our modelling approach closely follows the two-dimensional kinematic-dynamic models of ref. 25 but modified for three dimensions ${ }^{20}$. The model domain is a cartesian box (Supplementary Fig. 1) and is divided into four parts: (1) a kinematic slab, (2) a 40-km-thick rigid overriding plate, (3) a rigid wedge corner, and (4) a viscous mantle wedge (Supplementary Fig. 1). At the side boundaries with constant $x$-coordinate we impose symmetry boundary conditions, which imply zero normal velocity, zero heat flow and zero tangential stress. The effect of symmetry boundary conditions on finite strain calculations was tested by systematically moving their locations. The symmetry boundary conditions used in this work are adjusted so that they do not significantly affect finite strain calculations. The inflow and outflow boundaries are modelled as stress-free boundaries, much as they were in ref. 25. The geometries used for the segments of the Mariana and Andean subduction zones are shown in Supplementary Fig. $1 \mathrm{~b}$ and c.

Thermomechanical model. Fluid flow in the mantle wedge is governed by the conservation of momentum and mass for an incompressible infinite Prandtl number fluid and is driven by velocity boundary conditions that are parallel to the surface of the subducting slab. The magnitude of convergence velocity is set equal to $5 \mathrm{~cm} \mathrm{yr}^{-1}$. We ignore local buoyancy effects in the wedge. We have found that this approximation is appropriate for the employed dry rheological law based on a comparison of two-dimensional models with buoyancy forces, because the local Rayleigh number for secondary convection is near critical. Although we have observed transient effects, the steady-state flow geometry associated with these two-dimensional models is very similar to cases where flow is driven by the slab. Recent studies show that the addition of large quantities of water (hydrogen point defects) in localized regions ${ }^{15}$ and crustal foundering ${ }^{26}$ may give rise to small-scale convection in the mantle wedge. However, it is difficult to determine the effects of small-scale convection on fabric development from these studies because integrated finite strain calculations were not performed.

A temperature- and stress-dependent rheology is implemented in the viscous wedge. Specifically, we use the constitutive equation:

$$
\varepsilon_{\mathrm{t}, i j}=A \exp (-E / R T) \sigma^{(n-1)} \sigma_{i j}
$$

where $\varepsilon_{t, i j}$ are the components of the strain-rate tensor, $\sigma_{i j}$ are components of the stress tensor, $\sigma$ is the second invariant of the stress tensor, $T$ is the absolute temperature, and $R$ is the gas constant. We use $A=10^{-11.9} \mathrm{~s}^{-1} \mathrm{~Pa}^{-3}$, $E=510 \mathrm{~kJ} \mathrm{~mol}^{-1}$ and $n=3$, consistent with experiments on natural olivine aggregates $^{21,22}$. We impose a viscosity cut-off of $10^{26} \mathrm{Pas}$ to simulate lowtemperature creep mechanisms that limit the magnitude of deviatoric stress. Temperature is obtained by solving the time-dependent heat advectiondiffusion equation with constant thermal conductivity of $3 \mathrm{~W} \mathrm{mK}^{-1}$, heat capacity $\mathcal{c}_{\mathrm{p}}=1,250 \mathrm{~J} \mathrm{~kg}^{-1} \mathrm{~K}^{-1}$ and density $\rho=3,300 \mathrm{~kg} \mathrm{~m}^{-3}$ for the entire domain. The initial thermal condition is defined with a half-space cooling model with a cooling age of $50 \mathrm{Myr}$. The model evolution is followed for $20 \mathrm{Myr}$ of subduction. This duration of subduction is sufficient to reach steady state in the mantle wedge. Within the final velocity field we compute particle motion and finite strain using a fourth-order Runge-Kutta scheme. The initial position of tracers is defined by a uniform grid with $5 \mathrm{~km}$ spacing. Tracers are also injected into the base of the mantle wedge every 200,000 years. The computed finite strain is interpolated back to the uniform three-dimensional grid. The two-dimensional maps and cross-sections of finite strain (for example, Fig. 2a, b) are produced by spatial averaging with an averaging radius of $10 \mathrm{~km}$ to mitigate effects due to uneven particle coverage.

Numerical methods. The finite element package Sepran ${ }^{27}$ is used to discretize equations on a grid composed of linear tetrahedra. Strong local refinement is implemented in the corner of the wedge with a minimum resolution of $2 \mathrm{~km}$ along vertical planes with constant $x$-coordinates. Minimum resolution in the direction perpendicular to this plane is $5 \mathrm{~km}$ in the nose of the wedge to $10 \mathrm{~km}$ away from the regions with strong boundary layers. The maximum size of elements is $15 \mathrm{~km}$. The implicit Euler scheme is used for time integration with a dimensional time step approximately equal to twice the Courant-FriedrichsLevy criterion.

25. van Keken, P. E., Kiefer, B. \& Peacock, S. M. High-resolution models of subduction zones: implications for mineral dehydration reactions and the transport of water into the deep mantle. Geochem. Geophys. Geosyst. 3, doi:10.1029/2001DC000256 (2002).

26. Behn, M. D., Hirth, G. \& Kelemen, P. B. Trench-parallel anisotropy produced by foundering of arc lower crust. Science 317, 108-111 (2007).

27. Cuvelier, C., Segal, A. \& Van Steenhoven, A. A. Finite Element Methods and NavierStokes Equations (Reidel Publishing, Dordrecht, 1986). 